\title{
AC 2010-646: DESIGNING ROBOTIC SYSTEMS: PREPARATION FOR AN INTERDISCIPLINARY CAPSTONE EXPERIENCE
}

\section{William Michalson, Worcester Polytechnic Institute}

Dr. William R. Michalson is a Professor in the ECE Department at the Worcester Polytechnic Institute where he performs research and teaches in the areas of navigation, communications and computer system design. He supervises the WPI Center for Advanced Integrated Radio Navigation (CAIRN) where he is developing a Public Safety Integration Center focused on the integration of communications, navigation and information technologies for public safety applications. His research focuses on the development, test, and evaluation of systems for both civilian and military applications with a special emphasis on techniques focused on indoor, underground or otherwise GPS-deprived situations. Most recently, Dr. Michalson has been involved with the development and refinement of the Robotics Engineering curriculum at WPI.

\section{Fred Looft, Worcester Polytechnic Institute}

Fred Looft is a Professor and Head of Electrical and Computer Engineering at WPI. Dr. Looft has primarily been involved in computer engineering education at all levels, from introductory to graduate level advanced system architecture courses. With the advent of the WPI Robotics Engineering program, he has been involved in both course development and teaching at all levels, and with laboratory facilities development for the program. Dr. Looft's research interests have evolved from the analysis and modeling of tactile neural responses to now being focused on student capstone projects, systems engineering programs, and global education. Outside of the academic world, Dr. Looft is an avid sailplane enthusiast, pilot and flight instructor, and is a lifelong fitness enthusiast. 


\title{
Designing Robotic Systems: Preparation for an Interdisciplinary Capstone Experience
}

\begin{abstract}
The Robotics Engineering (RBE) program at the Worcester Polytechnic Institute officially began in 2009. Although the program had a small number of early graduates in 2009, based on current and projected enrollments it is expected that there will be a substantial number of students who will be graduating in 2010 and beyond.

When the number of program graduates is relatively low, advising students and scheduling sufficient time for student teams seeking to complete a capstone design project has a relatively small impact on faculty productivity. As the numbers grow, this impact becomes significant. For many institutions, this is a driving factor in the implementation of fourth year capstone design courses - that of efficiently managing faculty time.
\end{abstract}

\section{Background}

The field of Robotics is fundamentally multi-disciplinary, drawing on Electrical Engineering, Mechanical Engineering, Computer Science and many other academic disciplines. While many programs include Robotics as an element within a discipline such as Electrical of Mechanical Engineering, the Robotics Engineering Program at the Worcester Polytechnic Institute took a decidedly different approach.

Specifically, rather than looking at Robotics as an element within a larger engineering discipline, we have viewed Robotics as an engineering discipline unto itself, one which draws from other engineering disciplines but which, as in other disciplines, has an independent philosophy which underlies the application of technology to the solution of problems. Just as Mechanical Engineers solve problems using mechanical system analysis tools and pedagogy, and Electrical Engineers tend to solve problems using electrical system analysis tools and pedagogy, it is envisioned that Robotics Engineers will use robotic system analysis tools and pedagogy to solve problems. In other words, the philosophy which underlies Robotic Engineering is not merely to assemble a collection of electrical, mechanical and computer subsystems, but rather is the seamless integration of the correct robotic technologies into an optimized solution to a robotic problem. Further, while some design and analysis concepts are common to all engineering fields, different fields will employ unique approaches that are particularly suited to or require special emphasis within a specific discipline.

To gain depth of knowledge in fundamental engineering concepts, the academic program for students in Robotics Engineering includes selected courses in Electrical Engineering, Mechanical Engineering, Computer Science, Mathematics, Physics and other topics. However, to remain true to the underlying principles of the program, these courses are not the centerpieces of Robotics Engineering. Rather, there is a series of courses specifically in Robotics Engineering 
that seamlessly integrate electrical, mechanical and computer concepts in the context of building robotic systems.

The specific details of the courses have been the topic of several previous papers, however the core of the program consists of an Introduction to Robotics in the first year, followed by a series of four unified robotics courses which are normally taken in the second and third year[1-5]. The catalog descriptions of these courses are paraphrased below:

RBE 1001, Introduction to Robotics.

RBE 1001 is a multidisciplinary introduction to robotics, involving concepts from the fields of electrical engineering, mechanical engineering and computer science. Topics covered include sensor performance and integration, electric and pneumatic actuators, power transmission, materials and static force analysis, controls and programmable embedded computer systems, system integration and robotic applications.

RBE 2001, Unified Robotics I.

This is the first in a four-course core sequence. This course covers the conversion of electrical power to mechanical power, power transmission for locomotion, and payload manipulation and delivery. Concepts of energy, power and kinematics as well as concepts from statics (such as force, moments and friction) will be applied to determine power system requirements and structural requirements. Simple dynamics relating to inertia and the equations of motion of rigid bodies will be considered. Power control and modulation methods will be introduced through software control of existing embedded processors and power electronics.

RBE 2002, Unified Robotics II.

RBE 2002 is the second course in the four-course sequence. This course introduces the foundational theory and practice of robotics engineering, drawing from the fields of computer science, electrical engineering and mechanical engineering. The focus of this course is interaction with the environment through sensors, feedback and decision processes. Concepts of stress and strain as related to sensing of force, and principles of operation and interface methods for electronic transducers of strain, light, proximity and angle are be presented. Basic feedback mechanisms for mechanical systems will be implemented via electronic circuits and software mechanisms. The necessary software concepts will be introduced for modular design and implementation of decision algorithms and finite state machines.

RBE 3001, Unified Robotics III.

This is the third course in the four-course sequence. The focus of this course is actuator design, embedded computing and complex response processes. The course includes concepts of dynamic response as related to vibration and motion planning. The principles of operation and interface methods various actuators will be discussed, including pneumatic, magnetic, piezoelectric, linear, stepper, etc. Complex feedback mechanisms will be implemented using software executing in an embedded system. The necessary 
concepts for real-time processor programming, re-entrant code and interrupt signaling will be introduced.

\section{RBE 3002, Unified Robotics IV.}

This is the fourth course in the four-course sequence. The focus of this course is navigation, position estimation and communications. Concepts of dead reckoning, landmark updates, inertial sensors, vision and radio location will be explored. Control systems as applied to navigation are be presented. Communication, remote control and remote sensing for mobile robots and tele-robotic systems will be introduced. Wireless communications including wireless networks and typical local and wide area networking protocols will be discussed. Considerations will be discussed regarding operation in difficult environments such as underwater, aerospace, hazardous, etc.

All of the courses listed above have a significant laboratory component in which students must apply the concepts learned in class to laboratory projects which reinforce the concepts. It has proven critical to ensure that classroom study, homework and laboratory exercises are closely synchronized, since each element builds on the foundation of the previous elements.

It should be noted that while the RBE 1001 course is optional, it is expected that the Unified Robots I-IV courses will be taken in sequence by all Robotics Engineering students. There is some flexibility since each Unified Robotics course is currently being taught twice each year, so it is possible to start the unified sequence at the beginning or middle of the $2^{\text {nd }}$ year, or at the beginning of the $3^{\text {rd }}$ year. It is considered essential that all Robotics Engineering majors complete all four core courses before beginning a Capstone Design project in their $4^{\text {th }}$ year.

While this may appear to lack flexibility, it is currently considered essential to the underlying philosophy of the Robotics Engineering program as each course builds directly on the preceding course - reinforcing and extending robotics concepts in the true sense of a spiral curriculum. So far, our experience has indicated that by tightly integrating the electrical, mechanical and computer concepts in each course in a way that shows students how each concept applies to robotics, the retention of material by the students is improved and the students develop a sense that robots are not separate bits of electronics, mechanics and software that happen to be put in the same box. Allowing students to select core courses a la carte would significantly disrupt this synergy.

\section{Pre-Capstone Experience}

Once students have completed the core sequence of Unified Robotics courses, they should theoretically have the background necessary to complete a credible capstone design project. Indeed, since the first graduates of the Robotics Engineering program finished in 2009, several successful capstone design projects have been completed.

Example projects are more fully described in a companion paper in this proceedings, and include[2]: 
Robot research platform for locomotion through granular media:

This project is commonly referred as sand-swimming robot or snake robot among RBE students. The motivation for the project was the need for a platform to perform experiments and understand the dynamics of locomotion through granular media such as sand.

Hand-eye coordination in a humanoid robot:

Students were required to apply forward and inverse kinematics for robot manipulators and understand the controller for the humanoid robot Melvin

Design of low cost robotic manipulator joints:

Students were tasked to design low-cost, modular manipulator joints. The motivation for the project was to fill the gap between low quality hobbyist-type manipulator joints and highprecision, high-cost industrial ones.

In the early stages of our Robotics Engineering Program, when there were relatively few graduating students, it was possible to have a considerable amount of student-faculty interaction to aid students through the design process. As the number of graduating students requiring capstone design experiences has increased, however, it has become important that students beginning their capstone design projects have a more formal introduction to the engineering design process than is presented in the Unified Robotics core courses. In addition, it is considered important to provide students with an introductory overview of systems engineering as a discipline.

\section{Development of a Robotics Design Course.}

There is nothing new about the inclusion of robotics within a curriculum, or about the use of robotics to address capstone design. See generally [6-7]. However, in many situations robotics courses are developed such a way that they provide students from diverse backgrounds an introduction to the field of robotics, rather than an in-depth immersion in robotic technology. Certainly, such courses are valuable to expose students to technologies they might not otherwise see, but they necessarily require tradeoffs. Typically, such courses use pre-packaged robot kits, software or simulations to allow students with diverse backgrounds to interact with robots quickly. Associated with this tradeoff is the hiding of many of the details which underlie the electrical, mechanical and software decisions that must be made to truly build a robotic system.

In contrast, in the Robotics Engineering curriculum implemented at the Worcester Polytechnic Institute, we have made a conscious choice to expose the students to these details. As a result, we have traded accessibility of the courses to students outside the Robotics Engineering program for a deeper understanding of the comingling of technologies used to implement robotic systems. This, of course, has ramifications when teaching the design process in preparation for a capstone design project.

Previous experience within the Electrical and Computer Engineering Department has shown that a course which focuses on the process of design as early as a student's sophomore year has a significant positive impact on the ability of students to quickly decompose engineering problems into well-reasoned system designs.[8-9] In our multidisciplinary RBE program the same fundamental problem exists - how to teach students to decompose problems and how to methodically go about designing a complex system using well-known design engineering 
methodologies. Within the RBE context, the multidisciplinary aspects of the program increase the challenge of teaching the design process since the space in which tradeoffs occur increases significantly as trades now exist between implementations involving multiple disciplines (for example, what underlies the choice between an electrical or a mechanical braking system for a given design).

To address this problem, a course was developed to teach the central aspects of design in a multidisciplinary, robotics-oriented, engineering environment. Unlike a capstone design course, however, this new RBE course can be taken by a program student at any time prior to, and in fact during or after completing their ABET capstone requirement. The catalog description of the course includes the following text;

RBE 400X, Robot System Engineering and Design.

The designers of robotic systems start with a system requirement and must design the mechanical, electrical and software systems which must work together to achieve the goals of that system. Typically, parallel teams of engineers will work concurrently to create a working system within the time and budget constraints of the project, meaning that it is necessary to organize a project in such a way that parallel teams can work independently.

This course explores the tools and techniques used to develop complex systems. The topics covered include: requirements development; system architecture and partitioning; requirements flowdown; functional and interface specifications; trade studies; system modeling and simulation; system integration; as well as design verification and validation.

The focus of RBE $400 \mathrm{X}^{1}$ is clearly on the process of design - it is assumed that all students have completed the core sequence of courses, and therefore RBE 400X assumes that students have a sufficient understanding of this material to apply it. In other words, given a question within their knowledge domain they know how to come up with an answer. What they don't have is the experience or background necessary to determine what the correct questions are, and how to evaluate their answers. It is the purpose of RBE $4000 \mathrm{X}$ to provide this guidance.

\section{Implementation of RBE $400 X$}

The implementation of RBE400X was focused on a course project, and on lectures focused on topics related to the design process. Students in the course were divided into teams, and each team was tasked with developing (and justifying) their solution to the course project. By having a central project, it was possible to focus the lectures on providing information to project teams in an order that would help guide them through the decisions they would have to make at the time they needed to make decisions.

The project description used for the first offering of the course was:

\footnotetext{
${ }^{1}$ The "X" in RBE 400X denotes "experimental." In our institute it is common to have a limited number of experimental offerings of a new course before the course is adopted and assigned a permanent course number.
} 


\section{General Description}

You will develop a robotic system that carries a student's backpack that is expected to contain a laptop computer and several textbooks and notebooks. The robot will follow the student as s/he walks on the campus. When the student reaches a classroom building $\mathrm{s} /$ he will either lock the robot in a university-provided locker or carry the robot to class.

The robot must be able to navigate on flat and inclined paved surfaces at a reasonable walking speed (up to $4 \mathrm{mph}$ ). The robot must be able to have enough on-board power to operate for at least two hours without recharging. Students should be able to recharge the robot by plugging the robot into a wall power outlet.

Each team must develop a design which satisfies at least the following requirements:

\section{Structural Requirements}

- Should be able to climb a 30 inclined paved surface..

- Should be able to travel at up to $4 \mathrm{mph}$.

\section{Power Requirements}

- The robot must be operated by on-board batteries.

- Total power consumption must not exceed 15W.

- Battery should last at least 2 hours or runtime.

\section{Sensor Requirements}

- Must be equipped with sensors to follow the student.

- Must be equipped with sensors to avoid obstacles.

\section{Software Requirements}

- Should have intuitive user interface

- Must contain modular software components and provide for expansion.

\section{Other Requirements}

- Must be affordable.

- Must have an appealing look.

The design description provided to the students was purposely vague, and purposely had elements that might not be possible in combination with the other requirements. Such vagaries and inconsistencies are important because it is precisely this ambiguity that in the corporate world leads different engineering design teams down different paths towards a solution to a design problem. While students are somewhat uncomfortable with this at first, it is impressed on them that the "correct" design choice lies not in the specification, but on developing an understanding of the product, their market, budget, knowledge base, available time and other factors.

The classroom experience was team-taught by two professors. While any given lecture was assigned to one faculty member, both faculty members were present in most classes. This 
allowed faculty to ask each other questions in class, so that students could see, in real-time, the interaction between experienced designers and how they approached the same problem in different ways.

There were a total of 28 lectures in the class. The first 24 lectures explored specific topics in the design process and lead students through example problems which were related to the subsystems they needed to design for their projects. While the subsystems students were designing were not specifically addressed, at each step the essential tradeoffs that students had to make were presented in detail.

The detailed syllabus used in the first offering of the course is presented below:

\begin{tabular}{|ll|}
\hline \multicolumn{1}{|c|}{ Lecture } & \\
\hline Lecture 1 & Where does a design start? Goals and requirements \\
\hline Lecture 2 & Decomposing a system requirements specification \\
\hline Lecture 3 & Determining realistic requirements \\
\hline Lecture 4 & Top-Down Design - Developing a design concept \\
\hline Lecture 5 & Decomposing a system into a collection of subsystems \\
\hline Lecture 6 & Specifying system components in terms of function \\
Lecture 7 & Interface specs, who talks to who, why and who - the use of standards \\
\hline Lecture 8 & The role of simulation and modeling in system design \\
\hline Lecture 9 & Types of simulation tools \\
\hline Lecture 10 & Simulating mechanical systems \\
\hline Lecture 11 & Simulating electrical systems \\
\hline Lecture 12 & An overview of formal systems engineering \\
\hline Lecture 13 & The systems engineering life cycle \\
\hline Lecture 14 & Physical definition, designation, validation of requirements \\
\hline Lecture 15 & Using simulation to refine/validate systems design specifications \\
\hline Lecture 16 & Risk analysis, management, mitigation \\
\hline Lecture 17 & Testing, design for testing, what to test, validating tests \\
Lecture 18 & Reliability, reliability analysis and reliability testing \\
\hline Lecture 19 & Manufacturability, producibility, maintainability \\
\hline Lecture 20 & Creating safe designs, ethics \\
\hline Lecture 21 & Software engineering, configuration management, management tools \\
\hline Lecture 22 & What “ " should I use? (x = motor, battery, diode, microprocessor, etc) \\
\hline Lecture 23 & Intellectual property: how to create and/or use IP \\
\hline Lecture 24 & Wrapping up \\
\hline Lecture 25 & CDR - Team 1 \\
Lecture 26 & CDR - Team 2 \\
\hline Lecture 27 & Design Defense - Team 1 \\
\hline Lecture 28 & Design Defense - Team 2 \\
\hline
\end{tabular}


The format of the last four lectures is somewhat unconventional. Given the relatively small number of students in the class, there were only two teams. This allowed having each team take an entire lecture period to make a presentation of their design. In this Critical Design Review (CDR), students delivered a presentation of their final design, and their justifications for various design elements, to the faculty running the course. After the CDR, copies of the presentation and a final report were turned in by each team.

After each team made their presentation, a subsequent lecture was used to allow both the faculty (after a detailed review of the reports), and the other team, to ask detailed questions about the previously presented design. By dividing this process across two lecture periods for each team, it allowed teams to "fix" details in their reports and presentations which they realized were not presented well.

\section{Homework Assignments}

While the CDR process allowed evaluating the entire team's result, it was also necessary to have some measure of each individual student's contribution to the project. To accomplish this, there were team and individual contributor assignments which were evaluated each week.

The overall goal of the course was to deliver a design; however that delivery comprised a sequence of system and subsystem specifications. Thus, the first homework assignment involved decomposing the incomplete system specification the students were given into a set of real engineering requirements, and into definitions of the various subsystems that were required.

This approach allowed having each student take responsibility for a subsystem, forcing the team to divide the project into multiple parts with clear inter-relationships. This approach also allowed for adjusting the overall project scope to the number of students on the project team. For success, the team did not necessarily have to deliver an entire robot, they just had to deliver well-engineered portions of the overall robot as well as a well-engineered specification for those portions not designed.

Subsequent homework assignments, allowed individual students to concentrate on the design and tradeoffs associated with their individual subsystem, but also required students to communicate among themselves to ensure that decisions made at the subsystem level did not create inconsistencies in the overall design.

As the course progressed, and additional design techniques were introduced, the homework assignments required adding significant technical design content each week.

\section{Concluding Remarks}

RBE400X is still a work in progress and will be refined in subsequent offerings; however we believe that our first pass at teaching this course was sufficiently successful to continue offering the course. Student response in their course evaluations was uniformly positive, and showed that the students considered the course to be effective in increasing their understanding of the design process. 
As would be expected, the quality of the designs produced was variable, however those students graded at the A and B level clearly showed improvement in their technical skills and in their ability to reduce ill-specified problems into engineering specifications.

From the faculty perspective, there are some opportunities minimizing redundancy in lecture material, and it became obvious that more of the system engineering content should be presented earlier. This, however, is a difficult tradeoff between the benefit providing more formal system engineering material early and getting the students engaged with their projects early.

\section{References}

[1] G. Fischer, W. R. Michalson, T. Padir and G. Pollice," Development of a Laboratory Kit for Robotics Engineering Education" to appear, AAAI 2010 Spring Symposium on Educational Robotics and Beyond: Design and Evaluation, Mar. 22-24, Palo Alto, CA, 2010.

[2] G. Tryggvason, W.R. Michalson, et. al., Teaching Multidisciplinary Design to Engineering Students: Robotics Capstone," American Society of Engineering Educators 2010 Annual Conference, Louisville, KY, Jun 20-23, 2010.

[3] W. R. Michalson, et. al., "Unified Robotics: Balancing Breadth and Depth in Engineering Education", American Society of Engineering Educators 2009 Annual Conference, Austin, TX, Jun 14-17, 2009.

[4] G. Tryggvason, W.R. Michalson, et. al., "Robotics Engineering: A New Discipline for a New Century", American Society of Engineering Educators 2009 Annual Conference, AC 2009-997, Austin, TX, Jun 14-17, 2009.

[5] M. Ciraldi, W. Michalson, et. al., "The New Robotics Engineering BS Program at WPI," American Society of Engineering Educators 2008 Annual Conference, AC 2008-1048, Pittsburgh, PA, Jun 22-25, 2008.

[6] R. Manseur, "Development of an undergraduate robotics course," 27th Annual Frontiers in Education Conference, vol. 2, pp. 610-612, 1997.

[7] A. Saad, "Mobile robotics as the platform for undergraduate capstone electrical and computer engineering design projects," 34th Annual Frontiers in Education, vol. 3, pp. S2G 7-11, 2004.

[8] L. Polizzotto and W. R. Michalson, "The Technical, Process, and Business Considerations for Engineering Design," Frontiers in Education 2001, Reno, NV, pp. F1G-19-F1G-24, Oct 10-13, 2001.

[9] W.R. Michalson, S.J. Bitar and R.C.Labonte, "The Technical, Process, and Business Considerations For Engineering Design - A 10 Year Retrospective," in review, American Society of Engineering Educators 2010 Annual Conference, Louisville, KY, Jun 20-23, 2010. 